\title{
ANALISIS KESIAPAN PUSKESMAS DEMANGAN KOTA MADIUN DALAM MENGHADAPI AKREDITASI
}

\section{Readiness Analysis of Demangan Health Care Centre Madiun in Facing Accreditation}

\author{
Lailatul Maghfiroh, Thinni Nurul Rochmah \\ Bagian Administrasi dan Kebijakan Kesehatan Fakultas Kesehatan Masyarakat \\ Universitas Airlangga \\ (layla.fira@gmail.com,085712816850)
}

\begin{abstract}
ABSTRAK
Peningkatan kualitas kesehatan merupakan salah satu pelaksanaan wajib yang tertuang dalam pembangunan kesehatan nasional yaitu Rencana Pembangunan Jangka Menengah Nasional (RPJMN). Dalam pelaksanaannya, setiap pelaksana pelayanan kesehatan wajib untuk melakukan akreditasi untuk mewujudkan jaminan kualitas pelayanan kesehatan. Puskesmas Demangan merupakan salah satu puskesmas tingkat pertama di Kota Madiun dan berintegrasi dengan Badan Pelayanan Jaminan Kesehatan (BPJS) Kesehatan. Sesuai peraturan, Puskesmas Demangan harus mulai mempersiapkan akreditasi untuk puskesmas tingkat pertama guna mewujudkan penjaminan mutu pelayanan. Penelitian ini bertujuan mengetahui pencapaian awal penilaian akreditasi sesuai dengan pedoman Peraturan Menteri Kesehatan No. 46/2015. Penelitian ini termasuk penelitian deskriptif observasional dengan desain cross sectional. Telusur dokumen diidentifikasi sesuai dengan standar instrumen dan dilakukan wawancara untuk mengetahui pelaksanaan prosedur tersebut. Hasil penelitian menunjukkan bahwa pencapaian akreditasi sampai dengan Maret 2016 hanya sebesar 62,9\% dari semua elemen penilaian dalam standar akreditasi untuk kesiapan puskesmas dalam akreditasi. Rekomendasi penelitian ini mengarah ke pembentukan tim khusus untuk fokus ke dokumen dan monitoring evaluasi akreditasi.
\end{abstract}

Kata kunci: Kesiapan akreditasi, puskesmas, penjaminan mutu

\begin{abstract}
Improving the quality of health is one of the compulsory execution set out in the national health development namely the National Mid Term Development Plan (RPJMN). In practice, each implementing mandatory health care for accreditation to realize the quality assurance of health services. Demangan Community Health Center is one of the first-level health centers in Madiun and integrate with Health Insurance Service Agency (BPJS) Health. According to regulations, Demangan's health center should start preparing for the accreditation for first level health centers in order to achieve quality assurance services. This study aims to determine the initial achievement of accreditation assessment in accordance with the guidelines of the Minister of Health Regulation No. 46/2015. This research was descriptive observational cross-sectional design. A search documents identified in accordance with standard instruments and conducted interviews to determine the implementation of the procedure. The results showed that the achievement of accreditation until March 2016 only reached $62.9 \%$ of all elements in the assessment of accreditation standards for preparedness in the health center accreditation. Recommendations this research leads to the formation of a special team to focus on documents and monitoring and evaluation of accreditation.
\end{abstract}

Keywords: Accreditation, health centers, quality assurance 


\section{PENDAHULUAN}

Pembangunan kesehatan merupakan salah satu upaya yang sangat penting untuk mewujudkan derajat kesehatan masyarakat yang setinggi-tingginya. Pembangunan kesehatan di Indonesia dijabarkan dalam Rencana Pembangunan Jangka Menengah Nasional (RPJMN). Salah satu sasaran dari RPJMN 2015-2019 adalah meningkatkan mutu pelayanan kesehatan dasar dan rujukan terutama di daerah terpencil atau tertinggal.

Upaya peningkatan mutu pelayanan merupakan hal yang sangat penting untuk meningkatkan kualitas pelayanan bidang kesehatan. Peningkatan kualitas kesehatan ini bukan perkara yang mudah karena tidak hanya berlaku untuk fasilitas kesehatan tingkat lanjut seperti rumah sakit, tetapi juga berlaku untuk semua tingkatan pelayanan kesehatan dasar yaitu puskesmas. Menurut Hukormas BUK Kemenkes, indikator mutu pelayanan kesehatan adalah akreditasi. ${ }^{1}$ Akreditasi diperlukan dengan tujuan agar pelayanan kesehatan memiliki mutu dan mampu memberikan pelayanan yang berkualitas sesuai standar. ${ }^{2}$ Mutu pelayanan kesehatan harus dilaksanakan sesuai dengan kode etik dan standar pelayanan yang ditetapkan, sehingga menimbulkan kepuasan bagi setiap pasien. ${ }^{3}$

Penjaminan mutu pelayanan puskesmas sebagai fasilitas pelayanan kesehatan tingkat pertama di Indonesia masih memiliki keterbatasan dalam kelengkapan peralatan dan jenis pelayanan. Selain itu, masyarakat menganggap bahwa kinerja staf di puskesmas masih kurang profesional. Semua kondisi tersebut berkaitan dengan rendahnya insentif yang diterima staf puskesmas, lemahnya leadership dan keterampilan manajerial pimpinan maupun staf puskemas serta kurangnya pembinaan puskesmas oleh dinas kesehatan kabupaten $/$ kota. $^{4}$

Berdasarkan Peraturan Menteri Kesehatan Republik Indonesia Nomor 46 Tahun 2015 tentang Akreditasi Puskesmas, Klinik Pratama, Tempat Praktik Mandiri Dokter, dan Tempat Praktik Mandiri Dokter Gigi, pasal 3 menyatakan bahwa puskesmas wajib terakreditasi, dan Pemerintah Daerah berkewajiban untuk mendukung, memotivasi, mendorong, serta memperlancar proses pelaksanaan akreditasi puskesmas. ${ }^{5}$ Akreditasi juga merupakan salah satu persyaratan kredensial sebagai fasilitas pelayanan kesehatan tingkat perta- ma yang bekerjasama dengan BPJS, sebagaimana diatur dalam Peraturan Menteri Kesehatan Nomor 71 tahun 2013 tentang Pelayanan Kesehatan Pada Jaminan Kesehatan Nasional Pasal 6 ayat (2). ${ }^{6}$

Puskesmas Demangan merupakan salah satu puskesmas di Kota Madiun yang sedang mempersiapkan akreditasi pada tahun 2016. Berdasarkan laporan kunjungan rawat jalan Puskesmas Demangan tahun 2014-2015 menunjukkan jumlah peserta BPJS Kesehatan yang terdaftar semakin meningkat. ${ }^{7}$ Peningkatan ini seiring dengan visi Puskesmas Demangan menjadi puskesmas yang terbaik dalam pelayanannya. Mewujudkan visi tersebut tentunya Puskesmas Demangan harus senantiasa mengupayakan penjaminan mutu dalam pemberian pelayanan kesehatan. Upaya penjaminan mutu tersebut dapat dilakukan dengan mengikutsertakan Puskesmas Demangan dalam akreditasi puskesmas. ${ }^{1}$ Oleh karena itu, berdasarkan diseminasi hasil uji coba implementasi akreditasi puskesmas oleh Kemenkes RI hingga tahun 2015 serta dalam rangka upaya penjaminan mutu maka penelitian ini bertujuan mengetahui kesiapan awal Puskesmas Demangan dalam menghadapi akreditasi.

\section{BAHAN DAN METODE}

Penelitian ini dilakukan di wilayah kerja Puskesmas Demangan Kota Madiun. Penelitian ini bersifat deskriptif observasional dengan pendekatan kuantitatif. Rancangan penelitian ini menurut waktunya adalah desain cross sectional. Pengambilan data dilakukan di Puskesmas Demangan pada Maret-April 2016. Instrumen yang digunakan adalah Permenkes No. 46 tahun 2015 sebagai pedoman untuk observasi dan wawancara. Observasi dilakukan dengan panduan assessment dan telusur dokumen. Dokumen yang ditelusur sesuai dengan masing-masing elemen penilaian dari standar akreditasi. Dokumen yang dimaksud secara garis besar dibagi atas dua bagian yaitu dokumen internal dan eksternal. Dokumen internal akreditasi dapat berupa kebijakan, pedoman, Standar Prosedur Operasional (SPO), sedangkan dokumen eksternal akreditasi meliputi peraturan perundangan dan beberapa pedoman (regulasi) eksternal yang berlaku.

Pengambilan data dilakukan dengan metode wawancara untuk mendukung observasi dalam 
mengklarifikasi dokumen yang tidak diketahui. Populasi yang digunakan dalam penelitian ini adalah seluruh tim akreditasi puskesmas. Wawancara dilakukan pada seluruh tim akreditasi yang terlibat, diantaranya tim pokja (kelompok kerja) UKM, UKP dan Administrasi Manajemen. Tim pokja tersebut dibentuk dari seluruh anggota puskesmas baik itu pelaksana bagian sumber daya manusia, admin dan paramedik. Responden dalam penelitian ini berjumlah 22 orang. Jumlah ini adalah total sampling dari ketiga tim pokja akreditasi Puskesmas Demangan. Analisis data dilakukan dengan memberikan skor pada setiap elemen yang memiliki makna berdasarkan pedoman yaitu 0 (tidak terpenuhi), 5 (terpenuhi sebagian) dan 10 (terpenuhi). Keseluruan pencapaian skor berdasarkan standar akreditasi dikategorikan dalam persentase yaitu $\leq 20 \%$ tidak terpenuhi, $21-79 \%$ terpenuhi sebagian dan $\geq 80 \%$ terpenuhi.

\section{HASIL}

Hasil penelitian didapatkan informasi bahwa distribusi responden berdasarkan kelompok umur adalah pegawai terbanyak berumur 26-33 tahun sebanyak 10 orang $(45,5 \%)$ dan kelompok umur yang paling sedikit adalah 18-25 tahun hanya mencapai 2 orang $(9,1 \%)$. Tingkat pendidikan tertinggi responden mayoritas lulusan D3 mencapai 11 orang $(50 \%)$, dan pendidikan terendah adalah SMA yang hanya 1 orang $(4,5 \%)$. Untuk masa pengalaman kerja responden sebagian besar 6-10 tahun yang mencapai 10 orang $(45,5 \%)$ dan sebanyak 3 orang $(13,6 \%)$ yang sudah mengabdikan diri di puskesmas selama lebih dari 16 tahun (Tabel 1).

Berdasarkan hasil self assesment dan skoring terhadap elemen penilaian yang sudah dicapai Puskesmas Demangan untuk memenuhi standar akreditasi puskesmas, didapatkan hasil akhir bahwa Puskesmas Demangan pencapaian akhir masih diangka $62,9 \%$ atau dikategorikan terpenuhi sebagian. Hal ini menunjukkan bahwa kesiapan Puskesmas Demangan dalam menghadapi akreditasi belum sampai $65 \%$. Masih perlu kerja keras ekstra agar dapat mencapai akreditasi dengan terpenuhi seluruh elemen penilaiannya. Bab yang memiliki pencapaian tertinggi adalah Bab III Peningkatan Mutu Puskesmas (PMP) sebesar $85,9 \%$ atau sudah terpenuhi. Bab yang memiliki pencapaian te-
Tabel 1. Karakteristik Responden

\begin{tabular}{lcc}
\hline \multicolumn{1}{c}{ Karakteristik } & $\mathbf{n}$ & $\mathbf{\%}$ \\
\hline Kelompok Umur (tahun) & & \\
18-25 & 2 & 9,1 \\
$26-33$ & 10 & 45,5 \\
$34-41$ & 7 & 31,8 \\
$\quad>41$ & 3 & 13,6 \\
Pendidikan & & \\
$\quad$ SMA & 1 & 4,5 \\
D3 & 11 & 50,0 \\
S1 & 9 & 40,9 \\
S2 & 1 & 4,5 \\
Masa kerja (tahun) & & \\
1-5 & 4 & 18,2 \\
6-10 & 10 & 45,5 \\
11-15 & 5 & 22,7 \\
$>16$ & 3 & 13,6 \\
\hline
\end{tabular}

rendah adalah Bab IX Peningkatan Mutu Klinis dan Keselamatan Pasien (PMKP) yang hanya sebesar $20 \%$, artinya pada standar ini belum terpenuhi sesuai dan masih jauh dari standar akreditasi yang ditentukan (Tabel 2).

\section{PEMBAHASAN}

Penilaian assesment pada elemen penilaian dilakukan untuk mengetahui kesiapan Puskesmas Demangan Kota Madiun dalam menghadapi akreditasi puskesmas yang pertama. Akreditasi ini memang hal pertama yang dilaksanakan di Kota Madiun untuk menjalankan amanah sesuai dengan Peraturan Menteri Kesehatan No 46 Tahun 2015 tentang akreditasi puskesmas.

Standar akreditasi yang disusun terdiri dari tiga bagian yang terbagi dalam sembilan bab. Bab tersebut terdiri dari 772 elemen penilaian dengan skor pencapaian saat ini adalah 4.171 dari total keseluruhan skor 6.630. Pencapaian saat ini secara keseluruhan standar rata-rata sebesar $62,9 \%$, termasuk dalam kategori terpenuhi sebagian. Standar akreditasi yang memiliki elemen terbanyak terdapat pada Bab VII Layanan Klinis yang Berorientasi Pasien (LKBP) sebanyak 127 elemen penilaian. Jumlah elemen paling sedikit yaitu 32 elemen penilaian adalah standar akreditasi pada Bab III tentang Peningkatan Mutu Puskesmas (PMP).

Standar kriteria Bab I Penyelenggaraan Pelayanan Puskesmas (PPP) terdiri dari tiga standar, dan keseluruhan hasil pencapaian dikategorikan 
Tabel 2. Hasil Pencapaian Puskesmas Demangan Kota Madiun pada Maret 2016 dalam Menghadapi Akreditasi Puskesmas menurut Permenkes No 46 tahun 2015

\begin{tabular}{|c|c|c|c|c|c|}
\hline Bab & Standar akreditasi & $\begin{array}{l}\text { Jumlah elemen } \\
\text { penilaian }\end{array}$ & $\begin{array}{c}\text { Jumlah skor } \\
\text { per elemen } \\
\text { penilaian }\end{array}$ & $\begin{array}{c}\text { Skor } \\
\text { pencapaian }\end{array}$ & $\begin{array}{l}\text { Persentase } \\
\text { pencapaian }\end{array}$ \\
\hline $\mathrm{I}$ & $\begin{array}{l}\text { Penyelenggaraan Pelayanan } \\
\text { Puskesmas (PPP) }\end{array}$ & 59 & 590 & 340 & $57,6 \%$ \\
\hline II & $\begin{array}{l}\text { Kepemimpinan dan Manajemen } \\
\text { Puskesmas (KMP) }\end{array}$ & 90 & 900 & 495 & $55 \%$ \\
\hline III & Peningkatan Mutu Puskemsas (PMP) & 32 & 320 & 275 & $85,9 \%$ \\
\hline IV & $\begin{array}{l}\text { Program Puskesmas yang Berorientasi } \\
\text { Sasaran (PPBS) }\end{array}$ & 53 & 530 & 400 & $75,4 \%$ \\
\hline V & $\begin{array}{l}\text { Kepemimpinan dan Manajemen } \\
\text { Program Puskesmas (KMPP) }\end{array}$ & 102 & 1020 & 820 & $80,4 \%$ \\
\hline VI & Sasaran Kinerja dan $M^{2} G^{e e}$ (SKM) & 55 & 550 & 295 & $53,6 \%$ \\
\hline VII & $\begin{array}{l}\text { Layanan Klinis yang Berorientasi } \\
\text { Pasien (LKBP) }\end{array}$ & $\begin{array}{c}151 \\
(\text { Opsional 24)* }\end{array}$ & 1270 & 930 & $73,2 \%$ \\
\hline VIII & $\begin{array}{l}\text { Manajemen Penunjang Layanan Klinis } \\
\text { (MPLK) }\end{array}$ & $\begin{array}{c}172 \\
\text { (Opsional 85)* }\end{array}$ & 870 & 500 & $57,5 \%$ \\
\hline IX & $\begin{array}{l}\text { Peningkatan Mutu Klinis dan } \\
\text { Keselamatan Pasien (PMKP) }\end{array}$ & 58 & 580 & 116 & $20 \%$ \\
\hline & Total Pencapaian & 772 & 6630 & 4171 & $62,9 \%$ \\
\hline
\end{tabular}

Keterangan : $\left(^{*}\right)$ opsional, penilaian tidak dilakukan pada elemen tersebut dan tidak terhitung pada penilaian

terpenuhi sebagian $(57,6 \%)$. Pada saat pengecekan masih terdapat dokumen yang belum tersedia ataupun belum dapat dipastikan apakah dokumen tersebut sudah ada ataukah memang belum dibuat oleh Puskesmas Demangan. Bab ini menggambarkan tentang analisis kebutuhan puskesmas, perencanaan, pelaksanaan sampai dengan evaluasi yang akan dilakukan. Keadaan ini belum sesuai dengan pendapat Bustami dalam upaya penjaminan mutu yaitu pencapaiannya lebih ditekankan pada proses pelayanan yang sesuai dengan standar sehingga mencegah terjadinya pelayanan yang tidak memenuhi standar karena pada akhirnya akan berdampak pada kepuasan pasien.

Pencapaian elemen terendah pada bab ini adalah pada standar akses dan pelaksanaan kegiat- an yang pencapaiannya hanya sebesar $39 \%$. Pencapaian ini dikategorikan terpenuhi sebagian atau masih banyak dokumen penunjang yang belum dimiliki. Pelaksanaan kegiatan yang kurang berjalan dengan lancar tentu berdampak pada hasil atau nilai yang diperoleh puskesmas apabila belum mencapai target dari perencanaan semula. Hal ini sesuai dengan pendapat Donot yang menyebutkan bahwa untuk mencapai suatu pe- rencanaan yang baik, pelaksanaan harus konsisten dan berkesinambungan, dengan maksud agar tujuan yang diinginkan dapat tercapai dengan efisien dan efektif. ${ }^{3}$

Pencapaian pada Bab II yaitu Kepemimpinan dan Manajemen Puskesmas (KMP) yang terdiri dari 6 standar. Pencapaian pada standar KMP sebesar 55\% atau sebagian terpenuhi. Dari enam standar yang ada, standar terendah adalah kontrak pihak ketiga yaitu pencapaiannya hanya sebesar $40 \%$. Pencapaian ini dikategorikan terpenuhi sebagian atau masih banyak dokumen penunjang yang belum dimiliki. Hal ini berdampak secara langsung pada manajemen puskesmas karena kontrak tersebut merupakan salah satu dokumen internal yang berperan untuk menjamin penyelenggaraan pihak ketiga memenuhi standar yang ditetapkan.

Kepemimpinan dan manajemen merupakan suatu hal yang penting. Menurut Bush dan Coleman dalam bukunya Manajemen Strategis Kepemimpinan, manajemen mutu dapat dilaksanakan dengan baik bila ada perbaikan secara terus menerus dan sebuah penekanan pada pencegahan daripada deteksi. ${ }^{8}$ Puskesmas Demangan membuktikan dengan standar pemeliharaan sarana 
dan prasarana yang memiliki pencapaian nilai tertinggi sebesar 74\%, kemudian disusul dengan manajemen pengelolaan lainnya seperti persyaratan puskesmas sebagai faskes tingkat pertama dan adanya kegiatan pengelolaan puskesmas.

Hasil pencapaian Bab III mengenai Peningkatan Mutu Puskesmas (PMP) dengan standar yaitu perbaikan mutu dan kinerja puskesmas konsisten dengan tata nilai, visi, misi dan tujuan puskesmas, dipahami dan dilaksanakan oleh Pimpinan Puskemas, Penanggung Jawab Upaya Puskesmas dan Pelaksana. Pada Bab III ini hanya terdapat satu standar dengan jumlah elemen penilaian 32 item yang pencapaiannya merupakan pencapaian tertinggi dibandingkan dengan bab lainnya yaitu sebesar $85,9 \%$. Hal ini menandakan bahwa peningkatan mutu puskesmas menjadi kegiatan utama dan banyak dokumen yang sudah ada bahkan sudah hampir semua dilaksanakan. Pencapaian ini dikategorikan sudah terpenuhi untuk elemen penilaiannya. Pencapaian yang tinggi ini dikarenakan standar pada elemen penilaian hanya satu standar yang terdiri dari 7 kriteria. ${ }^{9}$ Semua kriteria lengkap dan hampir semua sudah diimplementasikan, hanya pada standar ini belum dilakukan kaji banding ke puskesmas lain sehingga mengurangi nilai pada kriteria ketujuh. ${ }^{9}$

Standar kriteria Bab IV yaitu Upaya Kesehatan Masyarakat yang Berorientasi Sasaran (UKMBS) terdiri dari tiga standar dan keseluruhan hasil pencapaian dikategorikan terpenuhi sebagian $(75,4 \%)$. Hasil observasi menunjukkan bahwa masih terdapat dokumen yang belum tersedia atau belum dibuat oleh Puskesmas Demangan. Hal ini belum sesuai dengan pendapat Sulaeman bahwa puskesmas didirikan untuk memberikan pelayanan kesehatan dasar masyarakat yang menyeluruh, paripurna, dan terpadu bagi seluruh masyarakat melalui program dan upaya kesehatan yang diselenggarakan. ${ }^{4}$

Pencapaian elemen terendah pada bab ini adalah pada standar kebutuhan akan upaya kesehatan masyarakat dianalisis yang dicapai sebesar $56 \%$. Pencapaian ini dikategorikan terpenuhi sebagian atau masih banyak dokumen penunjang yang belum dimiliki. Standar ini kurang karena Puskesmas Demangan belum melakukan survei secara rutin untuk mengetahui kebutuhan dan harapan masyarakat, meskipun sudah ada kotak saran, teta- pi tidak berfungsi dengan maksimal.

Hasil pencapaian Bab V yaitu Kepemimpinan dan Manajemen Upaya Kesehatan Masyarakat yang terdiri dari 7 standar adalah sebesar $80,4 \%$. Nilai ini dikategorikan terpenuhi sebagian atau masih banyak dokumen penunjang yang belum dimiliki atau dibuat. Dari ketujuh standar yang ada, standar dengan pencapaian terendah adalah standar kebijakan dan prosedur pengelolaan. Hal ini diantaranya dikarenakan oleh pengendalian dokumen yang lemah seperti penomoran, catatan revisi, dan pemberlakuan oleh puskesmas. Selain itu dokumentasi hasil evaluasi dan monitoring juga belum terdokumentasi dengan baik sehingga elemen penilaian pada standar ini memiliki nilai yang rendah.

Pentingnya pelaksanaan dokumentasi yang baik dapat menjadikan pelayanan kesehatan lebih efektif dan efisien. Dokumentasi merupakan suatu catatan yang asli yang dapat dijadikan bukti hukum, jika suatu saat ditemukan masalah yang berhubungan dengan kejadian yang terdapat dalam catatan tersebut. Bukti pencatatan dan pelaporan di puskesmas berguna untuk kepentingan dalam memberikan pelayanan kesehatan dengan dasar komunikasi yang akurat dan lengkap secara tertulis. ${ }^{10}$

Hasil pencapaian Bab VI yaitu Sasaran Kinerja dan MDG's (SKM) dengan standar perbaikan kinerja masing-masing UKM Puskesmas konsisten dengan tata nilai, visi, misi dan tujuan puskesmas, dipahami dan dilaksanakan oleh Kepala Puskesmas, Penanggung jawab UKM Puskesmas dan Pelaksana yang ditunjukkan dalam sikap kepemimpinan mendapatkan nilai 53,6\%. Pencapaian ini dikategorikan terpenuhi sebagian untuk elemen penilaiannya. Kelemahan dalam bab SKM ini Puskesmas Demangan belum memenuhi beberapa elemen penilaian seperti pelaksanaan kaji banding (benchmarking). Kaji banding memiliki elemen penilaian yang cukup banyak dan belum dilakukan sepenuhnya oleh Puskesmas Demangan dan memiliki nilai paling rendah diantara standar lainnya (39\%).

Menurut United Nations, pembangunan kesehatan dengan cara pemenuhan sasaran kinerja dan MDG's dapat dilaksanakan dengan pembangunan yang berkelanjutan serta pembangunan yang mengakomodir beberapa prinsip yang mengerucut 
pada partisipasi, kesetaraan dan usaha-usaha untuk menguatkan kapasitas dan kemitraan global. ${ }^{11}$ Peningkatan sasaran kinerja ini meliputi perbaikan program pelaksanaan PONED (Pelayanan Obstetri Neonatal Dasar) untuk penurunan AKI (Angka Kematian Ibu) dan AKB (Angka Kematian Bayi), HIV/AIDS, dan penanggulangan TB dengan strategi DOTS. ${ }^{9}$

Pencapaian Bab VII mengenai Layanan Klinis yang Berorientasi Pasien (LKBP) yaitu sebesar $69,9 \%$. Pencapaian ini diklasifikasikan terpenuhi sebagian. Jumlah elemen penilaian yang belum terpenuhi cukup besar sehingga perlu mendapat perhatian khusus dalam persiapan akreditasi. Dalam bab ini ada 10 standar dan ada dua standar yang tidak dinilai (standar opsional) yaitu (1) makanan dan terapi nutrisi; (2) pemulangan dan tindak lanjut. Kriteria ini opsional karena dalam pedoman tidak mewajibkan ketersediaannya. Puskesmas Demangan saat ini tidak menyediakan layanan rawat inap sehingga standar tersebut tidak termasuk dalam penilaian.

Pencapaian terendah pada Bab VII adalah standar penyuluhan atau pendidikan kesehatan dan konseling kepada pasien/keluarga. Hal ini dikarenakan belum maksimalnya tenaga atau SDM untuk memberikan pendidikan kesehatan dan konseling serta belum lengkapnya bukti dokumentasi pelaksanaan, karena meskipun sudah terlaksana tetapi tidak ada bukti dokumentasinya maka dianggap belum dilakukan.

Pencapaian Bab VIII yaitu Manajemen Penunjang Layanan Klinis (MPLK) yang terdiri dari 7 standar. Pencapaian pada bab ini dikategorikan terpenuhi sebagian. Jumlah elemen penilaian yang belum terpenuhi cukup besar sehingga perlu mendapat perhatian khusus dalam persiapan akreditasi. Pencapaian yang hanya $57,5 \%$ karena Puskesmas Demangan belum menyediakan beberapa pelayanan yang dijadikan standar kriteria sedangkan standar kriteria yang opsional hanya dua yaitu (1) pelayanan laboratorium; (2) pelayanan radiodiagnostik. Hal tersebut karena dalam pedoman pelayanan bukan merupakan pelayanan penunjang yang wajib dimiliki oleh puskesmas.

Beberapa elemen dalam bab ini juga tidak memiliki skor atau tidak terpenuhi. Elemen tersebut adalah (standar kelima) lingkungan pelayanan mematuhi persyaratan hukum, regulasi dan peri- jinan. Hasil wawancara menunjukkan puskesmas selama ini tidak pernah melakukan kegiatan maupun pelayanan yang tidak mengindahkan lingkungan, tetapi puskesmas mengakui bahwa belum menyediakan dokumen terkait hal tersebut sebagai bukti pelaksanaannya. Kondisi ini dapat dihubungkan dengan penelitian sebelumnya oleh Hasibuan mengenai motivasi sumber daya untuk terlibat dalam proses akreditasi dipengaruhi peran para manajer melalui berbagai pendekatan tertentu sehingga sumber daya mau terlibat aktif khususnya dalam pendokumentasian dokumen yang dibutuhkan. ${ }^{12}$ Kita ketahui bahwa dalam proses akreditasi hal yang paling dibutuhkan adalah pendokumentasian dokumen yang baik terlebih dahulu kemudian melihat implementasinya. Jika sumber daya di puskesmas belum memiliki motivasi yang tinggi maka proses akreditasi akan sulit memiliki pencapaian yang tinggi. ${ }^{12}$

Bab IX yaitu Peningkatan Mutu Klinis dan Keselamatan Pasien (PMKP) terdiri dari empat standar merupakan bab yang memiliki pencapaian terendah dibandingkan yang lainnya dan dikategorikan tidak terpenuhi (20\%). Hasil tersebut menunjukkan bahwa puskesmas belum menjalankan standar mengenai keselamatan pasien begitu pula dengan kelengkapan dokumennya. Pencapaian terendah ini disebabkan kurang lebih sama dengan standar lainnya yaitu puskesmas belum memiliki beberapa dokumen penunjang yang menjadi bukti pelaksanaannya.

Puskesmas sebaiknya memprioritaskan standar dalam bab ini sesuai dengan kunci penjaminan mutu pelayanan kesehatan antara lain berpikir secara sistem, pendekatan saintifik, serta peningkatan mutu berkelanjutan. ${ }^{13}$ Faktor lain yang perlu diperhatikan dalam bab ini adalah keselamatan pasien yang besar pengaruhnya terhadap citra, tanggung jawab sosial, moral serta kinerjanya. Keselamatan pasien merupakan prioritas utama untuk dilaksanakan dan hal tersebut terkait dengan isu mutu dan citra. ${ }^{14}$

Secara keseluruhan standar rata-rata pencapaian berdasarkan elemen penilaian akreditasi, Puskesmas Demangan termasuk dalam kategori terpenuhi sebagian dengan rata-rata $62,9 \%$. Penilaian yang dilakukan menunjukkan bahwa dari seluruh standar pendokumentasian, banyak dokumen yang belum tersedia atau belum lengkap. 
Akreditasi tidak hanya melihat pencapaian atas standar tertentu, tetapi secara keseluruhan. Hal utama yang perlu diketahui bahwa akreditasi puskesmas bertujuan untuk meningkatkan mutu pelayanan yang berkesinambungan. ${ }^{5}$ Standar pelayanan puskesmas yang berlaku semua dinilai dan menghasilkan standar kualitas pelayanan untuk masyarakat.

Beberapa hal yang dapat dilakukan dalam penyiapan dokumen akreditasi $i^{15}$ adalah dengan membuat kerangka acuan terlebih dahulu. Selanjutnya menentukan metode yang akan digunakan, misalnya menggunakan metode angket atau metode wawancara. ${ }^{16}$ Hal berikutnya adalah menganalisis instrumen dengan merekap hasil yang didapatkan sesuai dengan metode yang digunakan. Hal ini terbukti cukup efektif guna pengerjaan dan pemenuhan dokumen serta memenuhi elemen penilaian sesuai dengan standar akreditasi yang ditetapkan.

\section{KESIMPULAN DAN SARAN}

Pencapaian Puskesmas Demangan dalam persiapan akreditasi puskesmas secara keseluruhan dari 663 elemen penilaian, pencapaian saat ini dengan skor 4.171 dalam persentase sebesar $62,9 \%$ atau dikategorikan terpenuhi sebagian. Pencapaian terendah yaitu pada standar akreditasi peningkatan mutu klinis dan keselamatan pasien. Pencapaian belum maksimal dikarenakan hampir seluruh dari elemen penilaian yang belum dimiliki adalah ketersediaan dokumen pendukung. Namun dengan adanya penilaian awal ini masih memungkinkan untuk dikembangkan pencapaiannya menjadi lebih besar sebelum pelaksanaan akreditasi, mengingat ini adalah penilaian pertama kali menggunakan dasar Permenkes Nomor 46 Tahun 2015 tentang Akreditasi Puskesmas, Klinik Pratama, Tempat Praktik Mandiri Dokter, dan Tempat Praktik Mandiri Dokter Gigi. Persiapan menghadapi akreditasi puskesmas yang dapat disarankan yaitu puskesmas sebaiknya membentuk tim yang khusus mempersiapkan dan melengkapi seluruh dokumen penunjang yang dibutuhkan untuk akreditasi agar lebih efisien dan terintegrasi dalam penyelesaian dokumen tersebut. Serta perlu adanya monitoring evaluasi yang dilakukan (self assesment) untuk mengetahui posisi dan ketercapaian puskesmas dalam menghadapi akreditasi.

\section{DAFTAR PUSTAKA}

1. Hukormas BUK Kemenkes RI. Diseminasi Hasil Uji Coba Implementasi Akreditasi Puskesmas di Provinsi Jawa Timur Dan Nusa Tenggara Timur. [Online].; 2015 [cited 2016 Juni 20. Available from: http://www.yankes.kemkes.go.id/readdirjen-buk-benahi-sistem-rujukan-yangtersendat-642.html.

2. Greenfield D, Pawsey M, Braithwaite J. What Motivate professional to engage in the accreditation of healthcare organizations? International Journal for Quality in Health Care 1011. 2010; 23(1).

3. Donot. Implementasi Manajemen Penilaian Kinerja Karyawan di Puskesmas 2 Mesuji Bandar [Tesis]. Lampung: Program Pascasarjana Magister Manajemen Universitas Lampung; 2016.

4. Sulaeman ES. Manajemen Kesehatan Teoritis dan Praktik di Puskesmas Yogyakarta: Gadjah Mada University Press; 2011.

5. Peraturan Menteri Kesehatan Nomor 46 Tahun 2015 tentang Akreditasi Puskesmas, Klinik Pratama, Tempat Praktik Mandiri Dokter, dan Tempat Praktik Mandiri Dokter Gigi.

6. Peraturan Menteri Kesehatan Nomor 71 tahun 2013 tentang Pelayanan Kesehatan pada Jaminan Kesehatan Nasional.

7. Puskesmas Demangan. Laporan Kunjungan Puskesmas Demangan tahun 2014 -2015 Surabaya: Universitas Airlangga; 2015.

8. Bush T, Coleman M. Manajemen Strategis Kepemimpinan Jogjakarta: IRCiSoD; 2008.

9. Direktorat Jendral Bina Upaya Kesehatan KKR. Standar Akreditasi Puskesmas Jakarta: Kemenkes RI; 2014.

10. Hutahaean. Konsep dan dokumentasi keperawatan. Jakarta: Trans Info Media; 2010.

11. United Nations. Goal: Ensure healthy lives and promote well-being for all at all ages: United Nations; 2015.

12. Hasibuan M. Organisasi dan Motivasi: Dasar Pemikiran Produktivitas. kedua ed. Jakarta: Bumi Aksara; 2009.

13. Bustami. Penjaminan Mutu Pelayanan Kesehatan dan Akseptabilitasnya Jakarta: Erlangga; 2011.

14. Depkes RI. Profil Kesehatan Indonesia Jakar- 
ta; 2008

15. Kusuma P. Akreditasi Puskesmas: Pembahasan Bab 4 Kebutuhan Akan Upaya Kesehatan Masyarakat. Journal Kesehatan. 2016 Oct;
$\mathrm{I}(1)$.

16. Idris I. Analisis Kesiapan Puskesmas Dalam Implementasi Akreditasi di Kota Lhoksumawe. Universitas Sumatera Utara; 2015. 